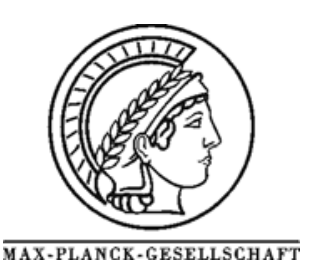

Chem. Comm. (2008) 4891-4893

\title{
Dynamic surface rearrangement and thermal stability of nitrogen functional groups on carbon nanotubes
}

\author{
R. Arrigo, M. Hävecker, R. Schlögl, D.S. Su,*, \\ Fritz Haber Institute of the Max Planck Society, Faradayweg 4-6, D-14195 Berlin, Germany \\ * Corresponding author: e-mail dangsheng@,fhi-berlin.mpg.de, Fax: 0049308413 4401; Tel: 00493084135406 \\ Received 24 July 2008; Accepted 28 August 2008; Available online 11 September 2008.

\begin{abstract}
Dynamic surface rearrangement and thermal stability of N-functional groups on carbon nanotubes (CNTs) obtained by functionalization of pristine CNTs with $\mathrm{NH}_{3}$ were studied by temperature-programmed XPS and MS. A link between the stability of the functional group and decomposi-
\end{abstract} \\ tion temperature have been established and a conversion into graphitic nitrogen was observed.
}

Keywords: Nitrogen, carbon nanotubes, x-ray photoelectron spectroscopy

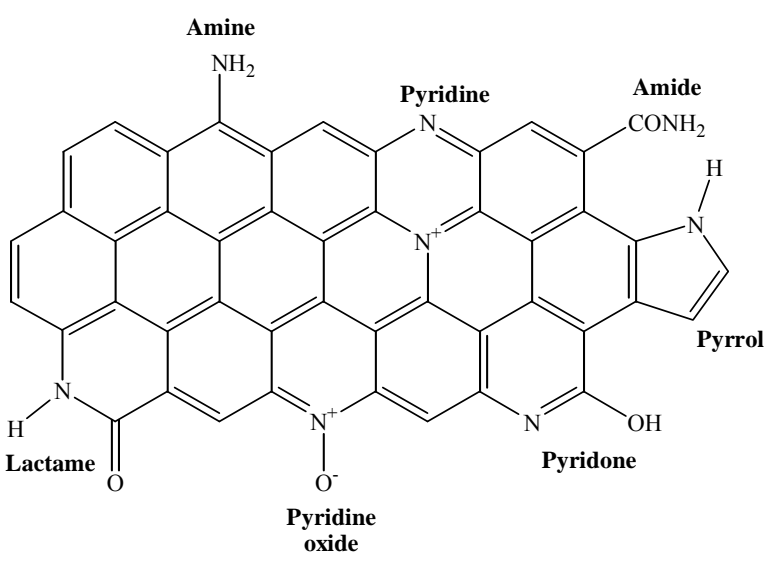

Scheme 1: Different types of nitrogen functionalities in graphite.

Tailoring the electronic, mechanical and chemical properties of CNTs by doping with elements such as N, B and $\mathrm{P}$ represents a significant challenge in modern nanotubes science. Recently, nitrogen functionalization of CNTs has specially drawn interests in heterogeneous catalysis because it induces surface modifications, which can enhance the activity in many catalytic applications in analogy to nitrogen in activated carbon [1]. In fact, N-containing CNTs manifest basic properties that have been exploited in fine chemistry synthesis. Nitrogen functionalization is beneficial for an uniform assembly of metal nanoparticles on CNT surface [2]. These interesting aspects stimulate researches aimed to synthesize N-containing CNTs with high nitrogen content $[3,4]$. Different nitrogen functionalities on carbon with quite different properties are reported $[5,6]$ and illustrated here in the scheme 1.

While the kind of nitrogen functionalities in carbon materials was reported to depend on the preparation conditions [7], the thermal stability of the nitrogen functional groups on carbon was still under investigation. This is of importance in view that the application of $\mathrm{N}$-functionalized CNTs, for instance in catalysis, may occur at elevated temperature. In this work we study the dynamic surface behaviour of N-functionalized CNTs and the thermal stability of the N-functional groups by Temperature Programmed Xray Photoelectron Spectroscopy (TP-XPS) with on-line Mass Spectrometry (MS). XPS is a suitable analytical technique for the assessment of nitrogen functionalities in carbon materials. When the sample is subject to a thermal treatment, surface modification of the functional groups occurs that can be monitored by XPS and the gas release by on-line MS. Once all possible functional groups are known, a consistent fit of the recorded spectra during TP- XPS can be done to follow the dynamic behaviour of individual $\mathrm{N}$ functional groups and therefore their thermal stability. Thus, the experiment allows a direct characterization of the 
nitrogen functional groups on the surface and the secondary species generated by their decomposition.

We use a post synthesis treatment, with $\mathrm{NH}_{3}$, to introduce nitrogen functionalities on the surface of CNTs. In a typical experiment, commercial multiwalled CNTs (MWNT, Pyrograp Products Inc.) are treated with nitric acid ( $20 \mathrm{~g}$ of CNT per liter of $\mathrm{HNO}_{3}$ ) at $373 \mathrm{~K}$ for $2 \mathrm{~h}$ under continuous stirring then rinsed until the washing water turns on neutral $\mathrm{pH}$. The sample was then dried at $343 \mathrm{~K}$ overnight. The aminated sample is obtained by thermal treatment of pre-oxidized CNTs ( $10 \mathrm{~g}$ for each batch) in ammonia flow $\left(0.2 \mathrm{Lmin}^{-1}\right)$ at $873 \mathrm{~K}$ for $4 \mathrm{~h}$. The surface $\mathrm{N}$ abundance determined by XPS using homogeneous distribution model is 9 at $\%$. The sample is referred as $\mathrm{N}$ CNT873K.

Table 1

\begin{tabular}{ccccc}
$\begin{array}{c}\text { Type of Ni- } \\
\text { trogen }\end{array}$ & $\begin{array}{c}\text { Pyridine Ni- } \\
\text { trogen }\end{array}$ & $\begin{array}{c}\text { Pyrrol and } \\
\text { pyridone } \\
\text { (lactame) }\end{array}$ & $\begin{array}{c}\text { Quaternary } \\
\text { Nitrogen }\end{array}$ & $\begin{array}{c}\text { N-oxide of } \\
\text { pyridine ni- } \\
\text { trogen }\end{array}$ \\
$\begin{array}{c}\text { BE(eV) } \\
\text { Literature }\end{array}$ & $\begin{array}{c}398.3-398.7 \\
{[12-17]}\end{array}$ & $\begin{array}{c}400.1-400.5 \\
{[12,14,16,19]}\end{array}$ & $\begin{array}{l}401.2-401.4 \\
{[12,15-17]}\end{array}$ & $\begin{array}{c}402.8-403.8 \\
{[12-15,17]}\end{array}$ \\
$\begin{array}{c}\text { This work } \\
\text { (eV) }\end{array}$ & 398.5 & 400.1 & 401.1 & 403.5 \\
\hline
\end{tabular}

${ }^{a} \mathrm{~N} 1 \mathrm{~s}$ core level XPS assignment for carbon material.

The XPS N1s core level spectrum of the sample and its deconvolution is reported in Fig.1. N1s spectra were calibrated versus $\mathrm{C} 1 \mathrm{~s}$ peak which is generally set to be at $284.6 \mathrm{eV}$ [8]. Three binding energy (BE) regions can be assigned to different nitrogen bonding in the N1s spectrum of model carbonaceous materials [9]: the pyridinic nitrogen region (labelled as $\mathrm{N} 1$, at about $398.5 \mathrm{eV}$ ), referred to nitrogen atom contributing to the $\pi$ system with one p-electron; the pyrrol region (labelled as $\mathrm{N} 2$, at about $400.1 \mathrm{eV}$ ), referred to nitrogen atom contributing with two p-electrons to the $\pi$ system. N2 composes the contribution of pyridone, lactame and pyrrol functional groups. The pyridone functionality is the tautomeric form of lactame functionality. The third region (labelled as $\mathrm{N} 3$, at $401-403 \mathrm{eV}$ ) is referred to the quaternary nitrogen, including protonated pyridine or the "graphitic" nitrogen when the nitrogen atom is incorporated in the graphene layer replacing carbon atom [13]. Furthermore, a peak labelled as N4 with a binding energy shift of $+5 \mathrm{eV}$ compared to pyridine is assigned to pyridine oxide. No contribution of amine or amide between $399-400 \mathrm{eV}$ has been found [10]. Table 1 summarizes literature data concerning assignment of the binding energies related to nitrogen species in carbon materials, and the binding energy values used in the present work for fitting the XPS spectra.

Fig. 2 displays the TPD-mass spectra during TPXPS. As it was reported earlier [11], nitrogen functional groups in carbon materials decompose during heating into

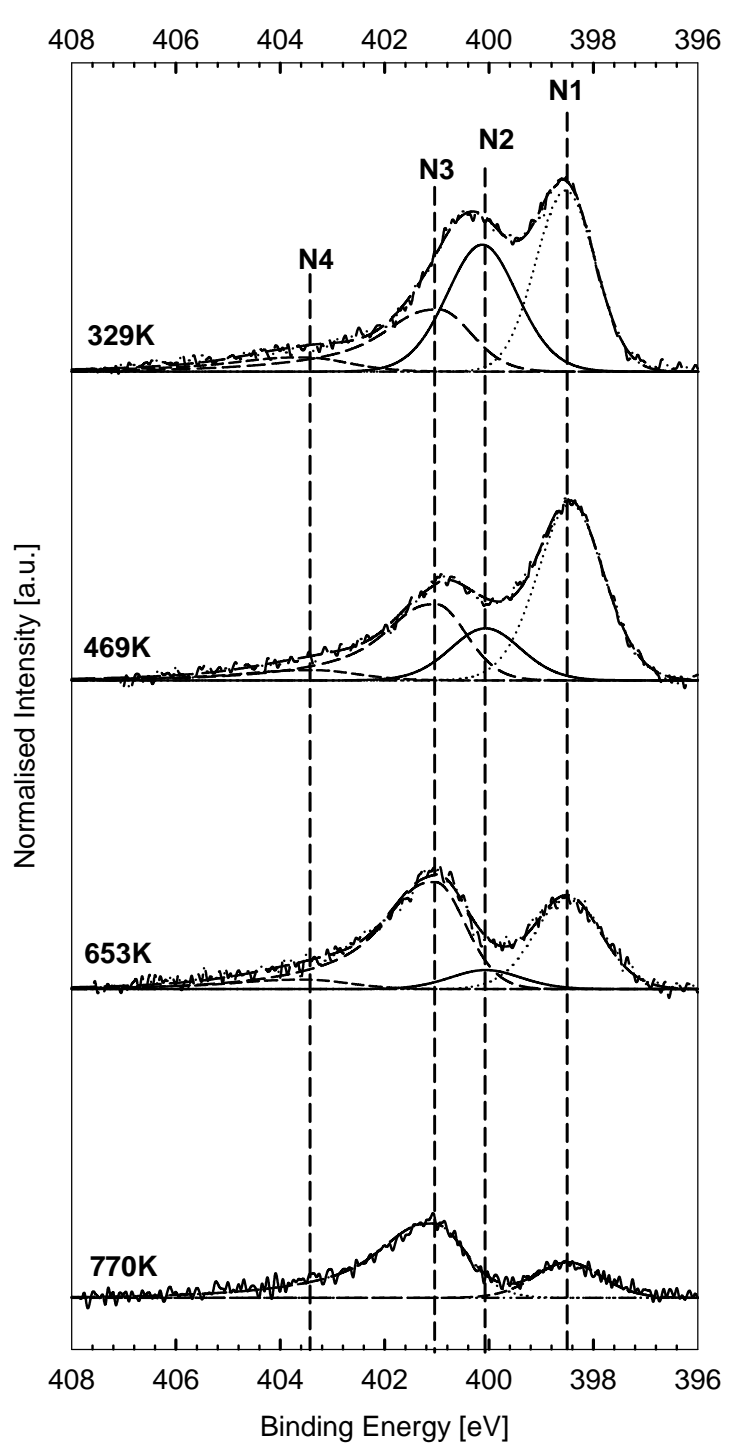

Fig. 1: Deconvoluted N1s core level spectra for sample NCNT873K during in-situ heating. N1at $398.5 \pm 0.1 \mathrm{eV} ; \mathrm{N} 2$ at $400 \pm 0.1 \mathrm{eV} ; \mathrm{N} 3$ at $401.1 \pm 0.1 \mathrm{eV} ; \mathrm{N} 4$ at $403.4 \pm 0.1 \mathrm{eV}$

$\mathrm{NH}_{3}, \mathrm{HCN}$, and in the most oxidized sample into NO. In this experiment, the main detectable signals are $\mathrm{HCN}(\mathrm{m} / \mathrm{z}$ 27), $\mathrm{NO}(\mathrm{m} / \mathrm{z} 30)$ and $\mathrm{N}_{2}(\mathrm{~m} / \mathrm{z} 14)$. The $m / z 27$ signals (Fig. 2 dotted line) exhibit over all the temperature range several features corresponding two different functional groups. The oscillation of this signal between $400 \mathrm{~K}$ and $660 \mathrm{~K}$ indicates a dynamic change of the $\mathrm{N}$-functional groups on carbon rather than a simple decomposition into gas molecules. In comparison with $\mathrm{HCN}$, signal assigned to $\mathrm{NO}$ is relatively low, and its evolution characteristics differ too. In particular it is linked to the lower thermal stable nitrogen functionalities. The $\mathrm{m} / \mathrm{z} 14$ is strictly related to the nitrogen functionalities, since it comes from fragmentation of those species. In fact it presents the same oscillation than $\mathrm{m} / \mathrm{z} 27$, specially at high temperature. It is still unclear whether the mechanism of formation for these species is homogeneous as a consequence of gas phase reaction between instable intermediate radicals generated during cracking of the functional groups, or heterogeneous if they are generated by 


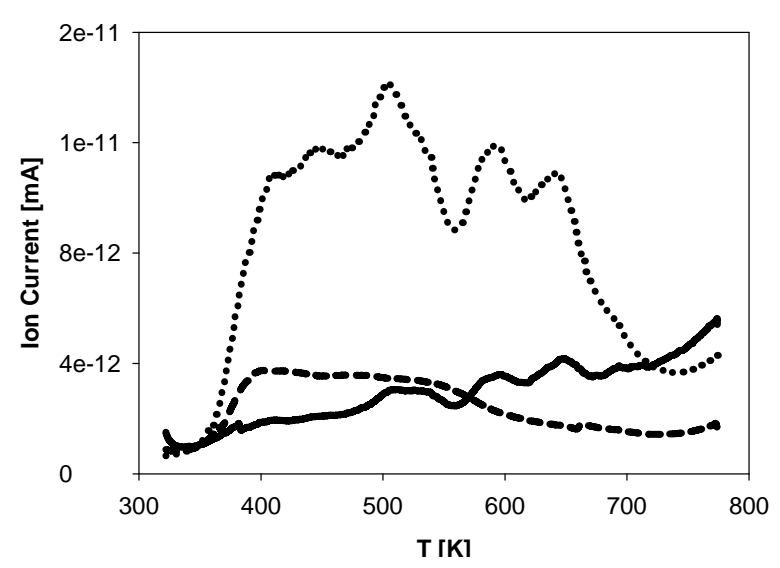

Fig. 2: Mass spectrum during in-situ TP-XPS for N-CNT873K: $\mathrm{m} / \mathrm{z} 27$ (dotted line); $\mathrm{m} / \mathrm{z} 30$ (dashed line); $\mathrm{m} / \mathrm{z} 14$ (full line).

surface rearrangements of the functional groups. According to literature [12], decomposition of functional group in nitrile ion gives rise to $\mathrm{HCN}$ when water is present. At low temperature is attributed to the decomposition of lactame groups, while to pyridine at higher temperature. More complicate is the understanding the cause of NO formation. It is probably due to dynamic surface rearrangement of moieties containing nitrogen and oxygen, e.g. lactame giving rise to NO in the mass spectrum. It could be also related to the decomposition of pyridine oxide species formed during the experiment. From Fig.2, it is clear that some of the nitrogen functionalities initially present in the sample are released in gas phase, with consequent decrease in the overall nitrogen content. However some functional groups are retained and undergo to dynamic surface rearrangement during heating. The evaluations of various components N1N4 versus temperature are plotted in Fig. 3. The N2 functionalities decrease continuously with increasing temperature. Since at the same time N1 and N3 components in the XPS spectra increase, lactame and pyrrol functional (N2) groups convert partly to these species.

Since water trace is detected by MS while N2 component decrease, we assume that lactame species are present with a binding energy of $400.3 \mathrm{eV}$, however, the presence of pyrrol groups can not be excluded. Lactame can dehydrate to pyridine functionalities, or can be thermally decomposed through formation of intermediate amide moieties that can further decompose giving both $\mathrm{m} / \mathrm{z} 27$ and $\mathrm{m} / \mathrm{z} 30$ corresponding to the first main feature in the mass spectrum. The pyridine total abundance reaches a maximum at $450 \mathrm{~K}$ and above this temperature starts to decrease (N1 curve in Fig. 3) while N3 still increase reaching a maximum at an higher temperature $(600 \mathrm{~K})$. Even in this case, a competition occurs between the structural transformation of pyridine into $\mathrm{N} 3$ and the decomposition in gas phase that give rise above $600 \mathrm{~K}$ to the second main feature in the $m / z 27$. Such processes occur in a wide range of temperatures so that the two pathways are overlapping each other. The N3 species is the most thermal stable species, it is generally referred in literature as quaternary nitrogen but

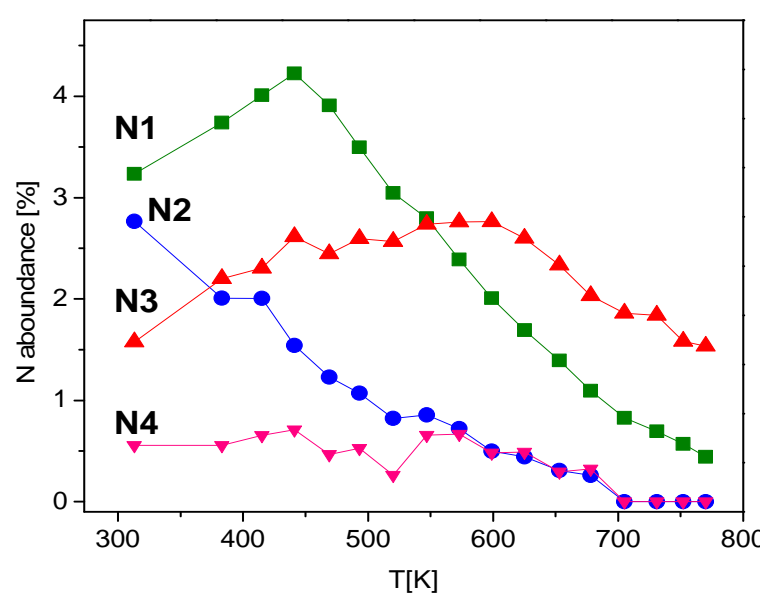

Fig. 3:Evolution of different N-species during TP-XPS for N-CNT 873:N1 (green curve); N2 (blue curve); N3 (red curve); N4 (pink curve)

the exact nature of this functionality is still poorly established. Early it was reported that an hypotetical structure of this functionality could be as reported in scheme2 [13]. Thus a surface reassembling of graphite cluster during heating occurs, leading to aromatization with introduction of a small amount of $\mathrm{N}$ in the graphitic structure. Scheme2 summarizes the modification of nitrogen functionalities during thermal treatment. Similar results have been reported earlier [13] for $\mathrm{NH}_{3}$ treatment on activated carbon.

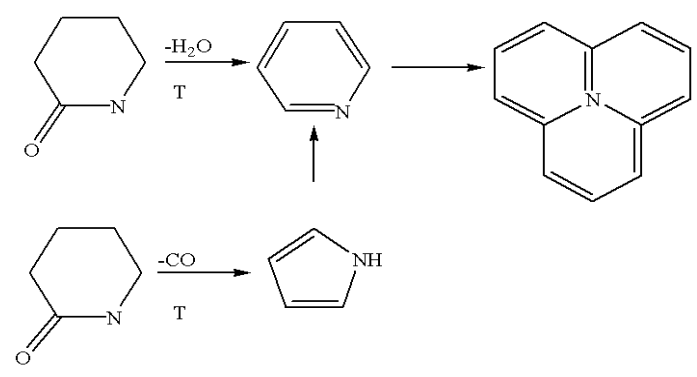

Scheme 2: Nitrogen insertion pathway in CNT

In summary, N-containing CNT is prepared by postsynthesis functionalization with $\mathrm{NH}_{3}$. It has been shown that TP-XPS is a suitable tool for the understanding of the N1s spectrum and assessment of nitrogen functionalities. Furthermore, it is possible to relate the mass signal and binding energy to certain specific functional groups. Although the decomposition of the functional group compete with the conversion to another functional group through a dynamic surface rearrangment that might depends on the heating rate and on the experimental pressure condition, a general trend was observed: initially functional groups with a binding energy at $400.3 \mathrm{eV}$ partly decompose through formation of $\mathrm{HCN}$, and partly convert into pyridine groups. Above $450 \mathrm{~K}$, pyridine are trasformed into graphitic nitrogen or decompose giving rise to further formation of HCN. Above this temperature graphitic nitrogen is the main species. Since the distribution of surface func- 
tional groups, remained in the carbon nanotubes surface, depends on the temperature, the procedure we present in this work allows to tune the acidic and basic properties of carbon nanotubes.

\section{References}

[1] B. Stöhr, H. P. Boehm, R. Schlögl, Carbon, 1991, 29, 707

[2] X. Li, Y. Liu, L. Fu, L. Cao, D. Wei, G. Yu and D. Zhu, Carbon, 2006, 44,, 3139

[3] R. Sen, B. C. Satishkumar, A. Govindaraj, K. R. Harikumar, G. Raina, J. Zhang, A. K. Cheetham and C. N. R. Rao, Chem. Phys. Lett, 1998, 287, 671 .

[4] M. Terrones, R. Kamalakaran, T. Seeger and M. Rühle. Chem Comm , 2000, 23, 2335

[5] L. R. Radovic, I. F. Silva, J. I. Ume, J. A. Menéndez, C. A. Leon Y Leon and A. W. Scaroni., Carbon, 1997, 35, 1339

[6] C. P. Ewels et al., J. Nanosc. Nano, 2005., 5, 1345

[7] S. van Dommele, A. Romero-Izquirdo, R. Brydson, K.P. de Jong and J.H. Bitter, Carbon, 2008, 46,138

[8] N. M. Rodriguez, P. E. Anderson, A. Wootsch, U. Wild, R. Schlögl and Z. Paal, J. Cat. 2001,197, 365

[9] J. Casanovas, J. M. Ricart, J. Rubio, F. Illas, and J. M. Jiménez-

Mateos., J. Am. Chem. Soc., 1996, 118, 8071
[10] amide and amine functional groups are formed at lower $\mathrm{NH}_{3}$ treatment temperature. The manuscript is in preparation.

[11]J.P. Boudou, Ph. Parent, F. Suárez-García, S. Villar-Rodil, A. Martínez-Alonso and J.M.D. Tascón, Carbon, 2006, 44, 2452

[12] R.J.J. Jansen and H. van Bekkum, Carbon, 2007, 32, 1507

[13] J. R. Pels, F. Kapteijn, J. A. Moulijn, Q. Zhu and K. M. Thomas, Carbon, 1995, 33, 1641

[14] P. H. Matter, L. Zhang and U. S. Ozkan, J. Cat. 2006, 239,83

[15]E. Raymundo-Piñero, D. Cazorla-Amorós, A. Linares-Solano, J. Find, U. Wild and R. Schlögl et al. Carbon, 2002,40, 597

[16] A .N. Buckley Fuel Proces Technol 1994, 38,165

[17] K. Sta Î́czyk, R. Dziembaj, Z. Piwowarska and S. Witkowski, Carbon 1995, 33, 1383

[18] M. A. Wójtowicz, J. R. Pels and J. A. Moulijnet al, Fuel 1995, 74, 507 